\title{
Epithelial Ovarian Carcinoma at Amrita Institute, Cochin, Kerala; A 4 Year Experience.
}

\author{
Vijaykumar DK, Chitrathara K, Shekhar Sharma, Pavithran K, Kishore Kumar
}

Even though primary debulking surgery is the established standard of care in advanced epithelial ovarian cancer (EOC), optimal cytoreduction is not feasible in all patients (ranges from 20 to $80 \%$ ). Additionally, primary debulking surgery, although supported by impressive retrospective evidence, has no prospective evidence to support its claim to standard of care.

In our published experience with primary surgery vs. neoadjuvant chemotherapy (NACT) in advanced epithelial ovarian cancer [IJMPO 2007;28(1):7-13], resectability is improved along with equivalence in terms of patterns and rates of failure. Subsequently we have updated the data and report the results here.

This is a retrospective evaluation of prospectively collected data of patients with EOC operated between March 2004 to Dec 2007 at the department of Surgical Oncology. Analysis was done using statistical software SPSS 11.0. Fischer's exact two-tailed test was used for analysis of significance and Kaplan Meier Graph for survival statistics.
Results: One hundred thirty four cases of EOC were operated (mean age 54.05 years) during the study period. Of these $111(83.0 \%)$ were in advanced stage $(82.3 \%$ stage IIIC, $8 \%$ stage IV and $9.7 \%$ recurrent malignancy). Of these $47.7 \%$ underwent primary cytoreductive surgery while $52.3 \%$ received NACT followed by interval debulking. The CA125 values were above $500 \mathrm{IU} /$ $\mathrm{ml}$ in almost $50 \%$ of the group. The pre treatment median CA 125 was $1243.5 \mathrm{IU} / \mathrm{ml}$ (range 1.78 to 7909 ) and the median duration of symptoms was four months.

The probability of optimal cytoreduction was higher in the NACT group than with primary surgery $(84.48 \%$ vs. $49.06 \% ; p=0.001)$. With a median follow up of over 22 months, $30.6 \%$ were alive and free of disease, $22.5 \%$ died of disease, $35.1 \%$ have developed recurrences or progressed with disease and $7.2 \%$ have only rising CA-125. Cases lost to follow-up accounted for $4.5 \%$.There were $29(54.7 \%)$ cases of recurrence after primary surgery and $35(60.3 \%)$ after NACT.

Table showing outcome of advanced ovarian ca, with a median follow-up of 2 yrs

\begin{tabular}{|l|c|c|c|}
\hline Follow-up status & Primary Surgery & NACT & Total \\
\hline NED & 18 & 16 & 34 \\
\hline Rising CA125 Only & 1 & 7 & 8 \\
\hline Alive with abd recurrence & 8 & 12 & 20 \\
\hline Alive with distant recurrence & 3 & 4 & 7 \\
\hline Alive with progressive disease & 6 & 6 & 12 \\
\hline Died of disease & 12 & 13 & 25 \\
\hline Lost to follow-up & 5 & 0 & 5 \\
\hline Total & 53 & 58 & 111 \\
\hline
\end{tabular}

Department of Surgical Oncology Amrita Institue of Medical Sciences \& Research Centre

Ela Makkara P.O. Cochin-682026 Kerala, India

E-mail: dkvijaykumar@aims.amrita.edu 
In both the groups pattern and rate of failure (distant, local and CA-125 rise) were similar ( $\mathrm{p}=$ NS). Interestingly, all patients, lost to follow up, were in the primary surgery group.

Conclusions: Our experience with NACT so far shows that it improves optimum debulking rates in advanced ovarian cancer. Additionally, outcome in both groups was similar. Though not measured objectively, surgical morbidity (including treatment costs) was definitely felt to be lesser in the neo-adjuvant chemotherapy group. When compared to our previous analysis 2 years ago, there has been a slight increase in the number of advanced ovarian ca coming for primary surgery. With more experience and building of a team, we feel more confident to take up more cases for primary surgery now, than we did 3 years ago. However with increased morbidity and increased cost related to primary surgery and survival being similar, there is a tendency to prefer NACT over primary surgery. 